\title{
A Fast Localization of Multiple Harmonic Sources for Rectifier Loads by Utilizing Periodogram
}

\author{
M. Hatta Jopri ${ }^{1}$, A. Rahim Abdullah ${ }^{2}$, Mustafa Manap ${ }^{3}$, M. Rahimi Yusoff ${ }^{4}$, Tole Sutikno ${ }^{5}$ \\ ${ }^{1,2}$ Fakulti Kejuruteraan Elektrik, Universiti Teknikal Malaysia Melaka (UTeM), Malacca, Malaysia \\ ${ }^{3,4}$ Fakulti Teknologi Kejuruteraan, Universiti Teknikal Malaysia Melaka (UTeM), Malacca, Malaysia \\ ${ }^{5}$ Department of Electrical Engineering, Universitas Ahmad Dahlan (UAD), Yogyakarta, Indonesia \\ *Corresponding author: hatta@utem.edu.my
}

\begin{abstract}
This paper introduces a fast method to localize the multiple harmonic sources (MHS) for rectifier based loads in power distribution system by utilizing periodogram technique with a single-point measurement approach at the point of common coupling (PCC). The periodogram is a fast and accurate technique for analyzing and distinguishing MHS location in power system. Matlab simulation is carried out several unique cases on IEEE test feeder cases due to validate the proposed method. The identification of MHS location is based on the significant relationship of spectral impedance which are fundamental impedance $\left(Z_{1}\right)$ and harmonic impedance $\left(Z_{h}\right)$ that's extracted from an impedance power spectrum. It is verified that the proposed method is fast, accurate, and cost efficient in localizing MHS. In addition, this method also contributes $100 \%$ correct identification of MHS location.
\end{abstract}

Keywords: multiple harmonic sources identification, periodogram, rectifier load, spectral impedance

Copyright $@ 2017$ Universitas Ahmad Dahlan. All rights reserved.

\section{Introduction}

It is vital in the harmonic analysis to identify the multiple harmonic sources with a particular target to manage the issue associated with harmonic disturbances [1]. This issue continues stretching out because of the present improvement, and changes of past conventional power system loads into modern power electronic gadgets for instance, inverter, rectifier loads and known as a harmonic producing source (HPS) [2]. In the real power distribution system, MHS can be found at upstream and downstream at the point of common coupling (PCC) [3]. Distinctive procedures in order to identify MHS have been studied in numerous research. With respect to least square and Kirchhoff's current law, state estimation strategy is presented [4]. Nonetheless, state estimation method requires numerous transducer for measurement purposes and too costly [5]. In the meantime, the earliest method to identify the MHS is utilizing power direction method, in any case this method speculatively, not precise when some harmonics and current phase angle is more than $90^{\circ}$ [6]. To overcome this problem, a critical impedance method is introduced [7]. However, the procedure requires correct data of internal impedances of utility and customer side, meanwhile in practice it is hard to quantify these impedances values [8]. A harmonic current vector technique has additionally been proposed to fix these issues [9-11], whereby the estimation of the harmonic contribution with no need of exact date of client impedances. Nonetheless, it requires long estimation calculation of harmonic contributions and difficult to measure harmonic impedance at client side with a specific end goal to identify the MHS. In the previous study [12-14], a strategy known as harmonic source estimation is proposed utilizing Bayesian estimation and harmonic state estimation (HSE). This technique infers a high computational complexity and required the very high cost of distributed measurement system setup [15]. With an alternate approach utilizing two-points measurement approach, the author had proposed another technique by comparing the first measurement at the PCC and the second measurement at the HPS by using spectrogram method [16]. This approach gives a right data, nevertheless too expensive and difficult to be executed [17]. In common practice, where accuracy, precision and quick measurement are required, these procedures do not give the adequate result.

This paper proposes multiple harmonic source identification utilizing single-point estimation using periodogram, a new approach for identifying MHS with good accuracy, 
quickness and cost efficient. The periodogram is a fast technique for characterizing and identifying the multiple harmonic sources [1]. Furthermore, rectifier specifically will be utilized as MHS in the distribution power system. The measurement data are analyzed periodogram and represented in power spectrum representation. Moreover, the spectral impedance which is fundamental impedance, $Z_{1}(50 \mathrm{~Hz})$ and harmonic impedance, $Z_{h}$ at the PCC are estimated from the power spectrum. Finally, the significant relationship between $Z_{1}$ and $Z_{h}$ from the proposed method is used due to identifying the location of MHS.

\section{Methodology}

Localization of multiple harmonic sources is done with a single-point measurement utilizing periodogram technique.

\subsection{Periodogram}

The periodogram power spectrum represents the distribution of power signal over frequency and can be expressed as [10]:

$$
\begin{aligned}
& S_{v}(f)=\left|\frac{1}{T} \int_{-\frac{T}{2}}^{\frac{T}{2}} v(t) e^{-j 2 \pi f t} d t\right|^{2} \\
& V_{D C}(t)=\sqrt{\int_{\frac{\Delta f}{2}}^{\frac{\Delta f}{2}} S_{v}(f) d f}
\end{aligned}
$$

Where, $S_{v}(f)$ in the frequency domain; $v(t)$ is voltage waveform; $V_{D C}(t)$ is direct current voltage and $\Delta f / 2$ is system frequency.

\subsection{Principle of Proposed Method}

The implementation of single-point measurement at PCC for MHS localization are shown in Figure 1 and Figure 2. The position of multiple harmonic sources is categorized into three conditions. There are 3 conditions of MHS location by referring to the PCC:

1. Downstream: When MHS located at customer side.

2. Upstream: When MHS located at utility side.

3. Both streams: When MHS located between utility and customer side.

The measurement data are analyzed using periodogram and presented in power spectrum representation. Furthermore, the parameters of the power system will be estimated from the power spectrum and finally the identification of MHS location is based on the significant relationship of spectral impedance which are $Z_{1}$ and $Z_{h}$ at the harmonic frequency.

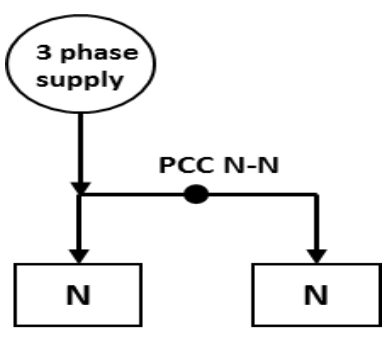

Figure 1. Case 1

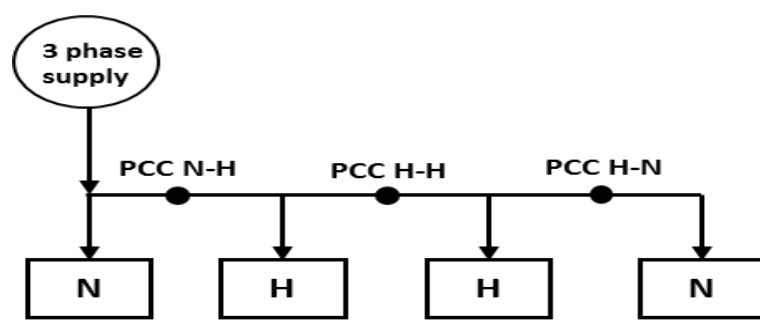

Figure 2. IEEE 4-bus test feeder for case 2, 3 and 4

Whereby, $\mathrm{N}$ is non-harmonic load and $\mathrm{H}$ is harmonic producing load.

\section{Results and Discussion}

The reliability of the proposed method is tested and verified on IEEE 4-bus test feeder with 3-phase full bridge rectifier that been utilized as the harmonic producing load. 


\subsection{Case 1: No Harmonic Sources in the System (NN)}

Figure 3(a) demonstrates the voltage and current in the time domain. The peak voltage and current were measured at 320.6V and 16.03A. Meanwhile, in Figure 3(b) it is observed that only the fundamental components of voltage and current exist at $50 \mathrm{~Hz}$. Figure 3(c) illustrates the power spectrum of power impedance and clearly shown that only $Z_{1}$ with a value of $20 \mathrm{ohm}$ is existed.
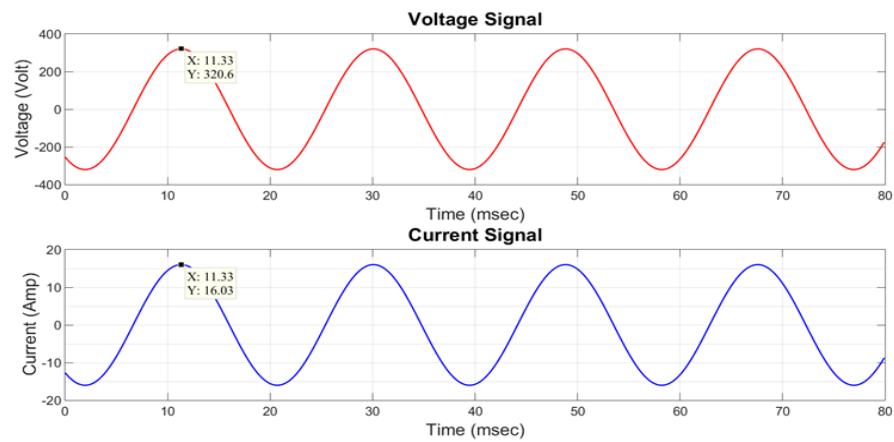

(a) Voltage and current signal in time domain
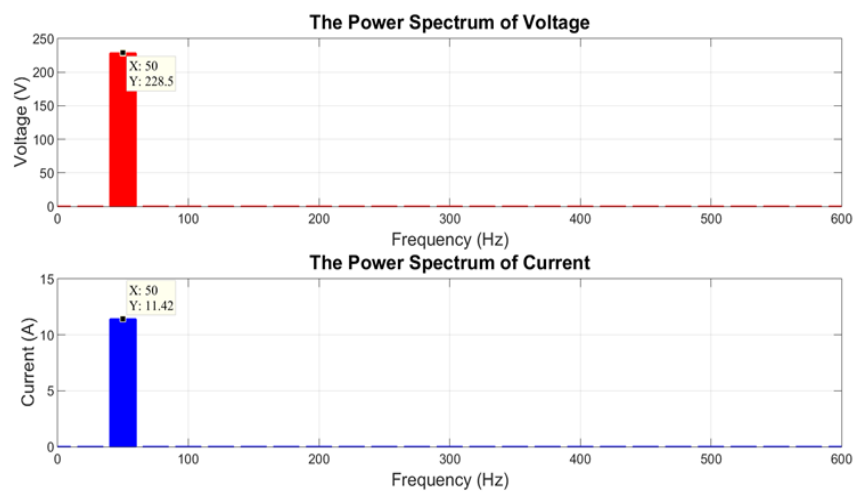

(b) The power spectrum of voltage and current

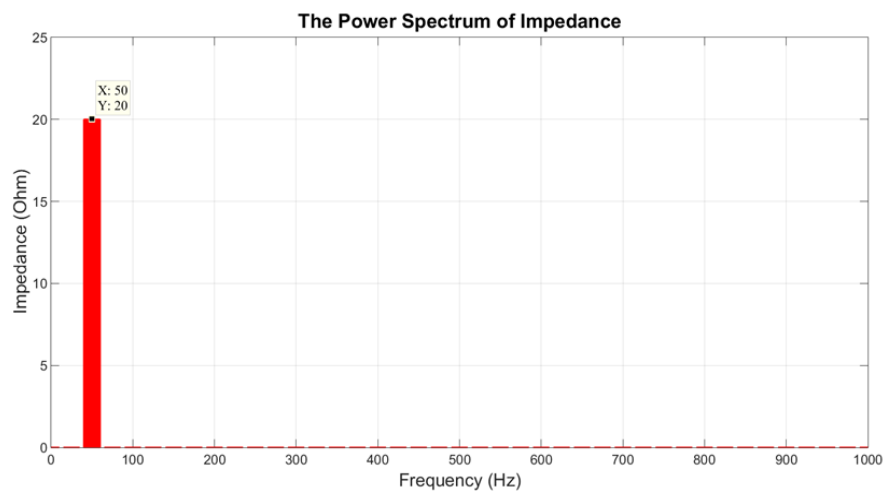

(c) The power spectrum of impedances

Figure 3. No harmonic Source in the System (NN)

Table 1. The Spectral Impedance for NN

\begin{tabular}{cc}
\hline Spectral impedance & Value $(\Omega)$ \\
\hline$Z_{50 h z}$ & 20 \\
$Z_{h}$ & 0 \\
\hline
\end{tabular}


It is evidently shown from the result that only the fundamental component is exist. Thus, the significant relationship between $Z_{1}$ and $Z_{h}$ can be finished up as:

$$
\begin{aligned}
& Z_{h}=0 \mathrm{ohm} \\
& Z_{1} \neq 0 \mathrm{ohm}
\end{aligned}
$$

\subsection{Case 2: Harmonic Sources at Downstream (NH)}

In case 2, the effectiveness of the proposed method is analyzed when harmonic source located at downstream. Figure 4(a) shows the voltage and current signal in the time domain with the highest peak value of 315.1V and 73.36A, respectively. As depicted in Figure 4(b), harmonic and inter-harmonic components exist at the frequency of $250 \mathrm{~Hz}, 375 \mathrm{~Hz}$ and $575 \mathrm{~Hz}$. The spectral impedance is shown in Figure 4(c), subsequently $Z_{1}$ is $4.206 \mathrm{ohm}$ and each value of $Z_{h}$ is always lower than $Z_{1}$.
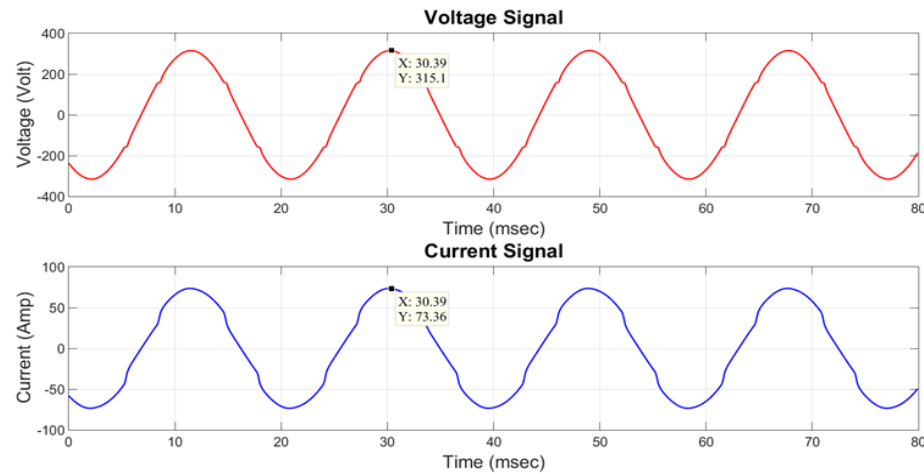

(a) Voltage and current signal in time domain
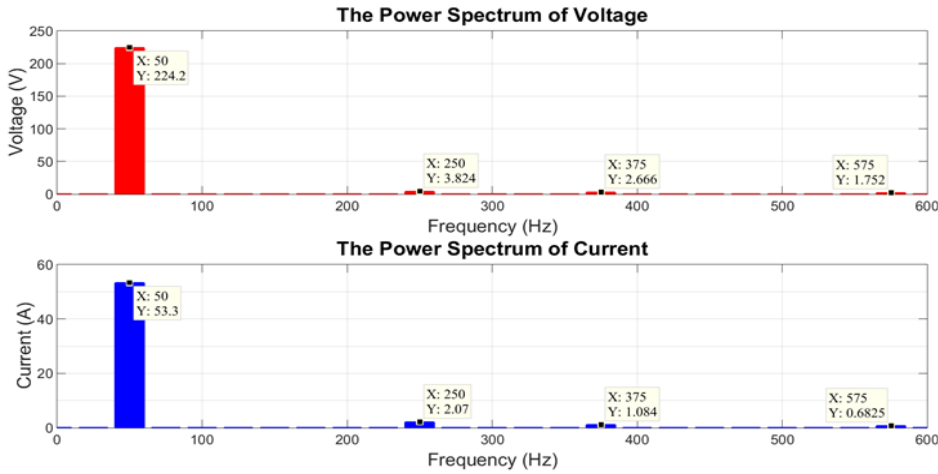

(b) The power spectrum of voltage and current

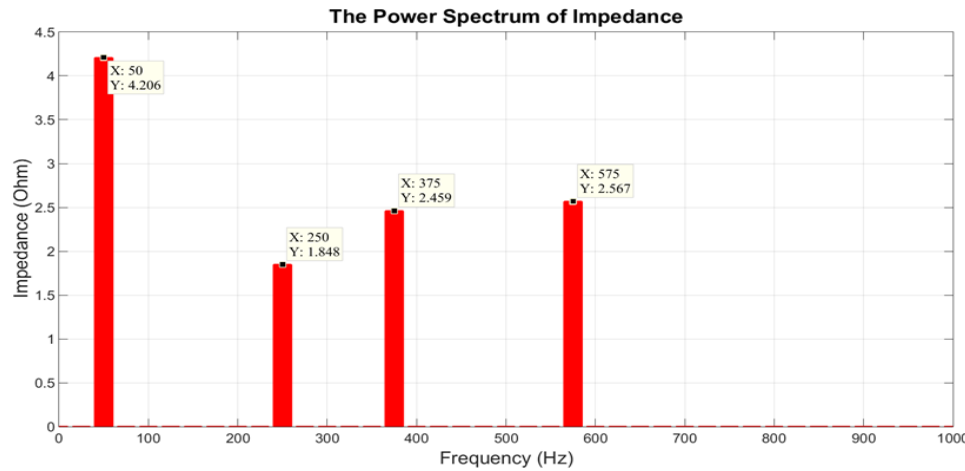

(c) The power spectrum of impedances

Figure 4. A harmonic Source at Downstream $(\mathrm{NH})$ 
Table 2. The Spectral Impedance for $\mathrm{NH}$

\begin{tabular}{cc}
\hline Spectral impedance & Value $(\Omega)$ \\
\hline$Z_{50 \mathrm{hz}}$ & 4.206 \\
$Z_{250 \mathrm{hz}}$ & 1.848 \\
$Z_{375 \mathrm{hz}}$ & 2.459 \\
$Z_{575 \mathrm{hz}}$ & 2.567 \\
\hline
\end{tabular}

The result from Table 2 obviously demonstrates that the $Z_{1}$ is always larger than the $Z_{h}$ at the downstream condition. Thus, the significant relationship of spectral impedance for the $\mathrm{NH}$ case can be concluded as:

$$
Z_{1}>Z_{h}
$$

\subsection{Case 3: Harmonic Sources at Upstream and Downstream (HH)}
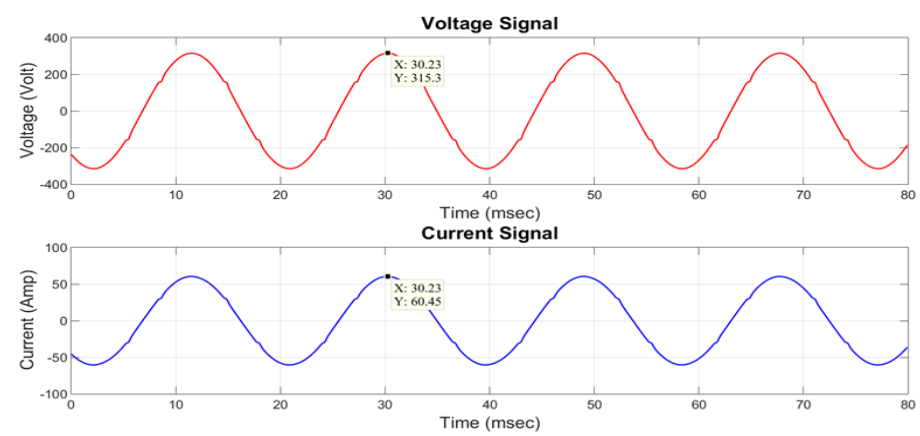

(a) Voltage and current signal in time domain
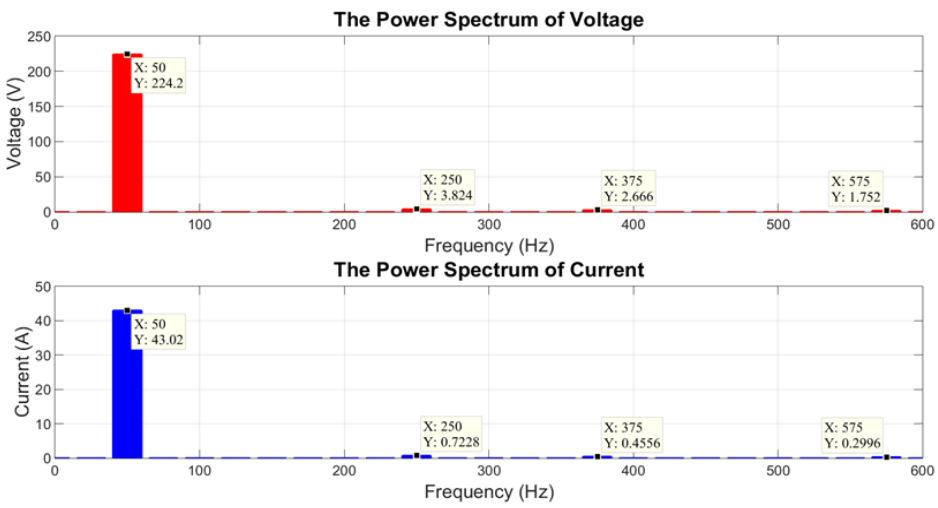

(b) The power spectrum of voltage and current

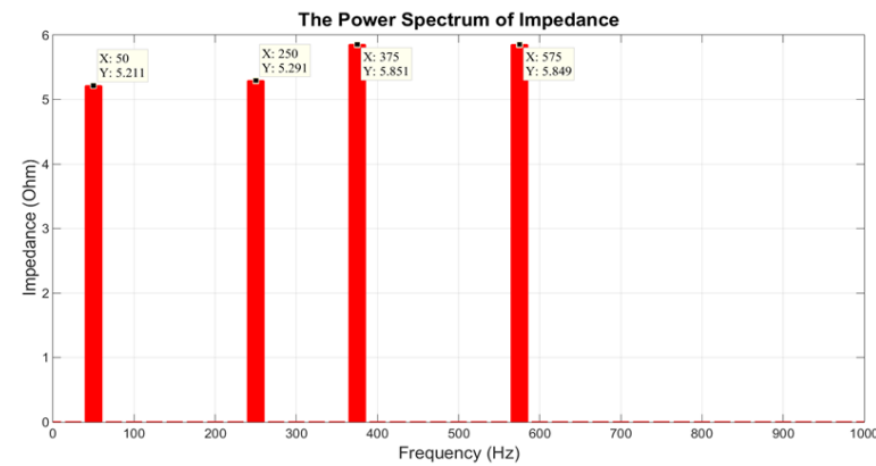

(c) The power spectrum of impedances

Figure 5. A Harmonic Source at Upstream and Downstream $(\mathrm{HH})$ 
The results achieved by the proposed method at the condition of the harmonic source located at downstream and upstream are shown in Figure 5(a), 5(b) and 5(c). The highest peak voltage and current are measured at $315.3 \mathrm{~V}$ and $60.45 \mathrm{~A}$, respectively. Meanwhile, harmonic and inter-harmonic components are detected at $250 \mathrm{~Hz}, 375 \mathrm{~Hz}$ and $575 \mathrm{~Hz}$. Moreover, the spectral impedance is demonstrated in Figure 5(c), afterward $Z_{1}$ is $5.211 \mathrm{ohm}$ and each value of $Z_{h}$ is always greater than $Z_{1}$.

Table 3. The Spectral Impedance for $\mathrm{HH}$

\begin{tabular}{cc}
\hline Spectral impedance & Value $(\Omega)$ \\
\hline$Z_{50 \mathrm{hz}}$ & 5.211 \\
$Z_{250 \mathrm{hz}}$ & 5.291 \\
$Z_{375 \mathrm{hz}}$ & 5.851 \\
$Z_{575 \mathrm{hz}}$ & 5.849
\end{tabular}

As shown in Table 3 , the outcomes for case 3 explain that the $Z_{1}$ is always smaller than the $Z_{h}$. Hence, the relationship of spectral impedance for $\mathrm{HH}$ case can be composed as:

$$
Z_{1}<Z_{h}
$$

\subsection{Case 4: Harmonic Sources at Upstream (HN)}
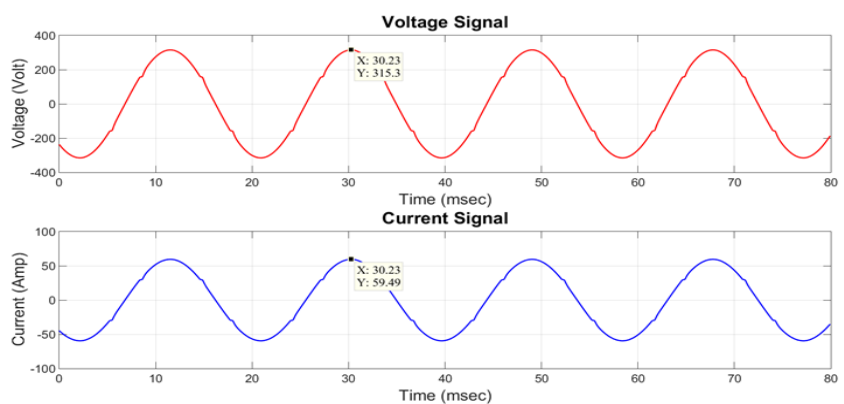

(a) Voltage and current signal in time domain
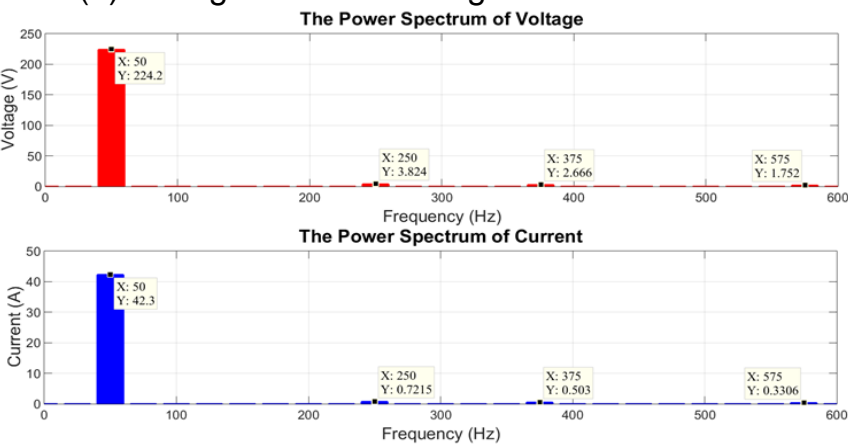

(b) The power spectrum of voltage and current

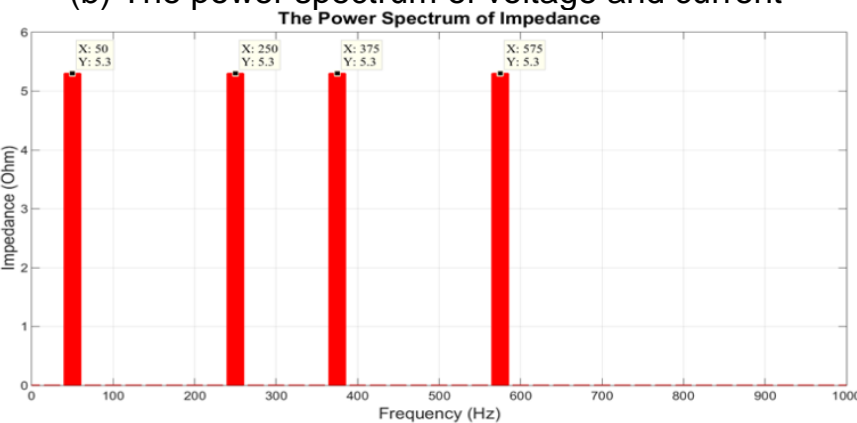

(c) The power spectrum of impedances

Figure 6. A harmonic Source at Upstream (HN) (a), (b), (c) 
In this case the proposed method is executed when the harmonic source located at the upstream side. Figure 6(a) presents the voltage and current signal in the time domain with a highest peak value of $315.3 \mathrm{~V}$ and $59.49 \mathrm{~A}$. In the meantime, Figure $6(\mathrm{~b})$ shows that the harmonic and inter-harmonic components were discovered at the frequency of $250 \mathrm{~Hz}, 375 \mathrm{~Hz}$ and $575 \mathrm{~Hz}$, respectively. The spectral impedance is shown in Figure 6(c), subsequently each value of $Z_{h}$ is equal with $Z_{1}$ with a value of $5.3 \mathrm{ohm}$.

Table 4. The Spectral Impedance for Case HN

\begin{tabular}{cc}
\hline Spectral Impedance & Value $(\Omega)$ \\
\hline$Z_{50 \mathrm{hz}}$ & 5.3 \\
$Z_{25 \mathrm{hz}}$ & 5.3 \\
$Z_{375 \mathrm{hz}}$ & 5.3 \\
$Z_{575 \mathrm{hz}}$ & 5.3 \\
\hline
\end{tabular}

The result tabulated in Table 4, clearly shows that the value of $Z_{h}$ is always same with $Z_{1}$ when the upstream condition is applied. Thusly, the significant relationship of spectral impedance for $\mathrm{HN}$ case can be finished up as:

$$
Z_{1}=Z_{h}
$$

The overall results of proposed method were tabulated in Table 5 and a clear significant relationship is observed between $Z_{1}$ and $Z_{h}$. The significant spectral impedance relationship can be plainly utilized for identifying the location of MHS in distribution power system.

Table 5. Spectral Impedance Characteristic for Multiple Harmonic Sources Identification

\begin{tabular}{cccc}
\hline Case & Upstream & Downstream & Spectral impedance characteristic \\
\hline 1 & $\mathrm{~N}$ & $\mathrm{~N}$ & $Z_{h}=0$ ohm \\
2 & $\mathrm{~N}$ & $\mathrm{H}$ & $Z_{1}>Z_{h}$ \\
3 & $\mathrm{H}$ & $\mathrm{H}$ & $Z_{1}<Z_{h}$ \\
4 & $\mathrm{H}$ & $\mathrm{N}$ & $Z_{1}=Z_{h}$ \\
\hline
\end{tabular}

Whereby, $\mathrm{N}$ is non-harmonic load, $\mathrm{H}$ is harmonic producing load, $Z_{1}$ is fundamental impedance and $Z_{h}$ is harmonic impedance.

\section{Conclusion}

The primary concern of this paper is to propose a fast localization of MHS with a singlepoint measurement approach by using periodogram analysis. The main contribution of this research is the significant relationship of spectral impedances which are $Z_{1}$ and $Z_{h}$ that been acquired from the power spectrum of impedance in identifying the location of MHS in distribution systems. In view of Table 5, the location of MHS in the distribution system can be identified and distinguished unmistakably as follow:

1. When the $Z_{h}$ is 0 ohm, no harmonic source exists in the system.

2. When the $Z_{1}>Z_{h}$, there is a harmonic source at downstream.

3. When the $Z_{1}<Z_{h}$, there is a harmonic source at upstream and downstream.

4. When $Z_{1}=Z_{h}$, there is a harmonic source at upstream.

Thus, considering above clarification, it is concluded that the proposed method is fast and accurate in identifying the MHS location in the distribution system.

\section{Acknowledgements}

This research is supported by Advanced Digital Signal Processing Laboratory (ADSP Lab). Special thanks also go to the faculty of electrical Engineering of Universiti Teknikal Malaysia Melaka (UTeM), Ministry of Higher Education Malaysia (MOHE) and Centre of Excellence CERIA, UTeM for giving the cooperation and funding to this research who make the research successfully. Their support is gratefully acknowledged. 


\section{References}

[1] S Nath, P Sinha, SK Goswami. A wavelet based novel method for the detection of harmonic sources in power systems. Int. J. Electr. Power Energy Syst. 2012; 40(1): 54-61.

[2] $\mathrm{N}$ Hamzah, A Mohamed, A Hussain. Identification of Harmonic Source at the Point of Common Coupling Based on Voltage Indices. J. Teknol. 2005; 43(1): 11-32.

[3] B Howe. A New vision of $P Q$ research for the next 10 years. In 2007 9th International Conference on Electrical Power Quality and Utilisation. 2007: 1-5.

[4] G D'Antona, C Muscas, S Sulis. State estimation for the localization of harmonic sources in electric distribution systems. IEEE Trans. Instrum. Meas. 2009; 58(5): 1462-1470.

[5] JE Farach, WM Grady, A Arapostathis. An optimal procedure for placing sensors and estimating the locations of harmonic sources in power systems. IEEE Trans. Power Deliv. 1993; 8(3): 1303-1310.

[6] W Xu. Power direction method cannot be used for harmonic source detection. In 2000 Power Engineering Society Summer Meeting (Cat. No.00CH37134). 2000; 2: 873-876.

[7] C Li, W Xu, T Tayjasanant. A 'Critical-Impedance' Based Method for Identifying Harmonic Sources. IEEE Power Eng. Rev. 2002; 22(9): 63-63.

[8] Z Staroszczyk, K Mikolajuk. New invasive method for localisation of harmonic distortion sources in power systems. Eur. Trans. Electr. Power. 2007; 8(5): 321-328.

[9] T Pfajfar, B Blažič, I Papič. Harmonic contributions evaluation with the harmonic current vector method. IEEE Trans. Power Deliv. 2008; 23(1): 425-433.

[10] B Blazic, T Pfajfar, I Papic. A modified harmonic current vector method for harmonic contribution determination. IEE PES Power Syst. Conf. Expo. 2004: 1049-1054.

[11] ME Balci, MH Hocaoglu. On the validity of harmonic source detection methods and indices. In Proceedings of 14th International Conference on Harmonics and Quality of Power - ICHQP 2010. 2010: $1-5$.

[12] G D'Antona, C Muscas, S Sulis. Localization of Nonlinear Loads in Electric Systems Through Harmonic Source Estimation. IEEE Trans. Instrum. Meas. 2011; 60(10): 3423-3430.

[13] G D'Antona, C Muscas, PA Pegoraro, S Sulis. Harmonic source estimation in distribution systems. Appl. Meas. Power Syst. (AMPS), 2010 IEEE Int. Work. 2010; 60(10): 1-5.

[14] G D'Antona, C Muscas, S Sulis. Harmonic source estimation: A new approach for the localization of nonlinear loads. 13th International Conference on Harmonics and Quality of Power. 2008: 1-6.

[15] KE Martin, G Benmouyal, MG Adamiak, M Begovic, RO Burnett, KR Carr, A Cobb, JA Kusters, SH Horowitz, GR Jensen, GL Michel, RJ Murphy, AG Phadke, MS Sachdev, JS Thorp. IEEE standard for synchrophasors for power systems. IEEE Trans. Power Deliv. 1998; 13(1): 73-77.

[16] NA Abidullah, GZ Peng, AR Abdullah. A new two points method for identify dominant harmonic disturbance using frequency and phase spectrogram. Int. Rev. Electr. Eng. 2014; 9(2): 453-459.

[17] AR Abdullah, GZ Peng, SA Ghani. A new vector draft method for harmonic source detection at point of common coupling. Proc. IEEE 8th Int. Power Eng. Optim. Conf. PEOCO 2014. 2014: 110-114. 